\section{Assessing predictive test bias with the microcomputer}

\author{
LEON D. LARIMER \\ Community Hospital of the Monterey Peninsula \\ Carmel, California 93921
}

and

\section{MARLEY W. WATKINS \\ Deer Valley School District \\ Phoenix, Arizona 85007}

There has been rising concern that many of the standardized educational and psychological tests in current use are biased when employed with culturally or economically disadvantaged populations (Golden, 1978). The significance of this issue has been demonstrated by the appointment of an American Psychological Association committee to investigate the use of standardized testing with disadvantaged students (Cleary, Humphreys, Kendrick, \& Wesman, 1975), by a federal mandate prohibiting the use of "biased" methods of assessment (The Education for All Handicapped Children Act of 1975, Note 1), and most recently by litigation relative to the use of intelligence tests to place minority school children in special education classes (Larry P. et al. vs. Wilson Riles et al., Note 2).

Peterson and Novick (1976), after reviewing a number of test-bias models, proposed a regression-based approach as the most viable method for assessing selection fairness within the predictive domain. Their suggestion was concordant with the recommendation offered by Cleary et al. (1975) that components of predictive test fairness are "directly translatable into regression statistics" (p. 25). While not without some debate (Thorndike, 1971), a regression-based approach for analyzing psychological test bias is being cited with increasing frequency in the testing literature (Bossard, Reynolds, \& Gutkin, 1980; Reschley \& Sabers, 1979; Reynolds \& Hartlage, 1979).

This paper presents a BASIC microcomputer program that calculates a regression model test of predictive bias developed by Potthoff (Note 3 ). The program provides both simultaneous and separate tests of regression slopes and intercepts for cases in which a single independent variable is used to predict to a single dependent variable. A significant $F$ for the simultaneous test indicates the presence of predictive bias. Separate tests of slopes and intercepts may then be conducted to determine whether the bias in prediction is constant (intercepts differ) or varies relative to the distance of scores from the mean (slopes differ).
Description. The program is written in Applesoft BASIC for the Apple II microcomputer. It occupies 4.3K of RAM memory and requires $1.5 \mathrm{~K}$ of additional RAM for every 100 subjects. Variables are mnemonic in character. The program is fully documented to facilitate adaption to other popular microcomputers. Input consists of number of groups, as well as predictor (X) and criterion $(Y)$ scores for each group member. Output includes group and total means for $X$ and $Y$, three $F$ ratios $(F 1=$ simultaneous test of slopes and intercepts, F2 = separate test of slopes, F3 = separate test of intercepts), and the probability value associated with each $\mathrm{F}$ ratio.

Availability. A source listing, complete with sample input and output, may be obtained from Leon D. Larimer, Mental Health Center, Community Hospital of the Monterey Peninsula, P.O. Box HH, Carmel, California 93921, upon receipt of a self-addressed envelope with 30 cents postage affixed.

\section{REFERENCE NOTES}

1. The education for all handicapped children act of 1975. Public Law No. 94-142, 89 stat. 773.

2. Larry P. et al. vs. Wilson Riles et al. 343 F Supp. 1306 (D.C.N.D. California, June 20, 1972).

3. Potthoff, R. F. Statistical aspects of the problem of biases in psychological tests (Institute of Statistics Mimeo Series No. 479). Chapel Hill, N.C: University of North Carolina at Chapel Hill, Department of Statistics, 1966.

\section{REFERENCES}

Bossard, M. D., Reynolds, C. R., \& Gutkin, T. B. A regression analysis of test bias on the Stanford-Binet Intelligence Scale for black and white children referred for psychological services. Journal of Clinical Child Psychology, 1980, 9, 52-54.

Cleary, T. A., Humphreys, L., Kendrick, S., \& Wesman, A. Educational uses of tests with disadvantaged students. American Psychologist, 1975, 30, 15-41.

Golden, C. J. Cross cultural second order factor structures of the 16PF. Journal of Personality Assessment, 1978, 42, 167-170.

Peterson, J., \& Novick, M. An evaluation of some models for culture fair selection. Journal of Educational Measurement, 1976, 13, 3-29.

Reschley, D. J., \& Sabers, D. L. Analysis of test bias in four groups with the regression definition. Journal of Educational Measurement, 1979, 16, 1-9.

Reynolds, C. R., \& Hartlage, L. Comparison of WISC and WISC-R regression lines for academic prediction with black and white referred children. Journal of Consulting and Clinical Psychology, 1979, 47, 589-591.

Thonndike, R. L. Concepts of culture fairness. Journal of Educational Measurement, 1971, 8, 63-70.

(Accepted for publication October 10, 1980.) 